\title{
ANALISA KERETAKAN PADA KONSTRUKSI GELADAK UTAMA KM. ADRI XLIV
}

\author{
Solichin Djazuli Sa’id \\ Program Studi Diploma III Teknik Perkapalan \\ Fakultas Teknik Universitas Diponegoro
}

\begin{abstract}
Solichin Djazuli Sa'id, in this paper explain that ship KM. XLIV Adri is the kind of cargo ship (General Cargo). The ship has been designed in accordance with the rules and regulations of the class (Bureau of Classification Indonesia). From the results of the survey method of research vessel, discovered the damage to construction on the main deck, the cracks on the fulcrum side deck fit the front room and deck beams are broken the back of the main deck. Thus causing the curvature of the floor deck and it needs to be a replacement / repair of components damaged by construction ensuring shipping safety. From the calculation results and field studies, construction damage caused by welding is not good, cutting the material that is not true and the use of payload on the main deck in excess of the permitted capacity.
\end{abstract}

Key words: Cargo Ship , Construction Damages, Main Deck

\section{PENDAHULUAN \\ Latar Belakang}

Setiap kapal yang akan dibangun harus memenuhi Standart/Rule yang telah ditetapkan oleh masing-masing Biro Klasifikasi. Rule dibuat dengan tujuan terpenuhinya kekuatan konstruksi, keindahan,dan yang paling penting adalah terjaminnya keselamatan pemakai kapal tersebut.

Hal-hal yang diatur oleh klasifikasi tidak hanya sebatas pada konstruksi saja, tetapi juga mengenai bahan/ material dan proses pengerjaan ( fabrication, fit-up,welding).

Faktor-faktor yang mempengaruhi terjadinya keretakan pada suatu konstruksi kapal antara lain :

- Pemakaian material baja yang tidak tepat.

- Proses pemotongan pada saat fabricatioan, fitup disetiap sambungan material

- Pengelasan yang tidak sempurna/ cacat las.

- Pembebanan yang berlebihan.

Oleh karena itu keretakan yang terjadi pada konstruksi dek utama Kapal KM ADRI XLIV sangat menarik untuk dilakukan penelitian dan dianalisa penyebab dari keretakan tersebut..

Kapal KM ADRI XLIV yang sedang melakukan floting repair di galangan PT. Jasa Marina Indah Semarang merupakan jenis kapal barang (General Cargo Ship)

Dari hasil pemeriksaan konstruksi dilapangan diketahui adanya kerusakan (keretakan) pada konstruksi Side Deck Girder sisi sebelah kiri (PS) pada ruang muat bagian depan dan balok geladak (Deck Beam) yang retak dibagian belakang sisi sebelah kanan (SB) Main Deck.

- Bagian belakang ruang muat (Cargo Hold) Terdapat keretakan pada sisi vertikal material siku 80 x 80 x 8 Deck beam pada frame no. 33 dan 35 sisi kiri (PS) konstruksi didaerah ruang muat bagian belakang, jarak keretakan dari lambung $400 \mathrm{~mm}$.

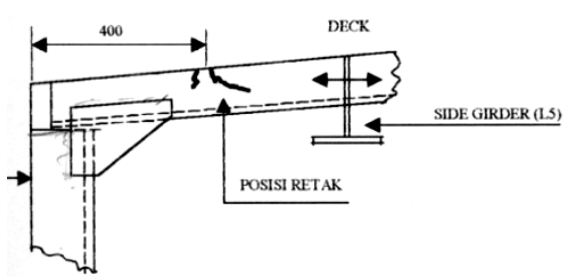

Gambar 1. Keretakan pada sisi vertikal

- Bagian depan Cargo Hold

Adanya keretakan pada penumpu geladak samping (Side Deck Girder) no. 5 pada frame no. 78 sisi kanan dan kiri, pelat sobek arah vertikal pada pelat bilahnya. Keretakan juga terjadi daerah tekukan pelat geladak dan pada bagian sudut lubang (Collar) atau lubang penembusan balok geladak, panjang keretakan $270 \mathrm{~mm}$

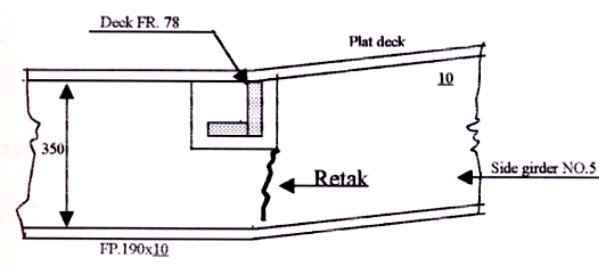

Gambar 2. Keretakan pada tekukan pelat

Untuk menentukan penyebab terjadinya keretakan pada konstruksi dek utama KM ADRI XLIV, dapat ditentukan dengan beberapa analisa, analisa dapat dilakukan dari hasil perhitungan yang didasarkan pada Rule yang ada, selain itu dapat juga dilakukan dengan analisa secara visual. Sehingga dari kedua analisa tersebut dapat diambil kesimpulan penyebab terjadinya keretakan pada konstruksi dek utama KM ADRI XLIV. 


\section{METODOLOGI}

Metode yang digunakan dalam penelitian ini yang terkait dengan keretakan konstruksi utama pada kapal KM ADRI XLIV adalah sebagai barikut :

- Tahap pertama survey pada kapal untuk mengamati dan meneliti konstruksi geladak yang terjadi keretakan-keretakan dan dilakukan pengukuran (panjang keretakan), kemudian diambil gambar (foto) sebagai bahan kajian selanjutnya.

- Tahap kedua survey pada kapal untuk pengambilan data-data yang meliputi ukuran utama kapal (Principal Dimension), jarak gading, jarak antara penumpu geladak, ukuran balok-balok geladak dan ukuran profil penumpu geladak.

- Tahap ketiga adalah melakukanan perhitungan-perhitungan antara lain :

o Perhitungan beban geladak

o Perhitungan beban sisi

- Tahap keempat :

o Perhitungan tebal pelat geladak

o Perhitungan tebal pelat sisi

o Perhitungan modulus penampang balok geladak dan ukuran profilnya

o Perhitungan modulus penampang penumpu geladak dan ukuran profilnya

- Tahap kelima merupakan analisa keseluruhan yang disertai dengan kesimpulan-kesimpulan dan secara analisis pencegahan keretakan pada konstruksi geladak.

\section{TUJUAN DAN MANFAAT}

Tujuan dari penelitian ini untuk mengkaji dan mengevaluasi penyebab terjadinya kerusakan pada konstruksi dek utama kapal KM ADRI XLIV.

Manfaat yang didapat dari penelitian ini sebagai bahan pertimbangan pada bangunan kapal baru khususnya pada proses prefabrication, fabricatioan, fit-up maupun welding, sehingga dapat memperkecil factor resiko yang akan diterima baik oleh pemilik maupun pemakai kapal dan sebagai bahan refrensi bagi perencana, pemesan kapal dan pihak galangan sebagai pembuat kapal.

\section{TINJAUAN PUSTAKA}

Konstruksi kapal merupakan salah satu factor yang memegang peranan penting dalam pembangunan kapal. Mengingat kapal adalah alat transportasi laut, maka segala sesuatunya harus memenuhi standart keselamatan baik ABK maupun penumpang.

Oleh karena itu untuk memenuhi standart kekuatan kapal dibuatkan aturan-aturan / rule tentang konstruksi kapal oleh biro klasifikasi, baik klas dari dalam negeri (Biro Klasifikasi Indonesia) maupun klas asing seperti American Bereau of Shipping (ABS), Germanischer Lloyd (GL), Nippon Kaiji Kyokai (NK) dan sebagainya.
Disamping rule-rule dari klas dapat dijumpai pula buku-buku konstruksi kapal yang dibuat oleh para ahli perkapalan, seperti : Merchant Ship Construction (DA. Tailor 1985), Ship Design and Construction (Robert Taggart 1980) dan masih banyak lagi buku-buku tentang konstruksi kapal, dimana buku-buku ini juga digunakan sebagai bahan literatur diperguruan tinggi dan dipakai pula sebagai bahan referensi oleh para perencana kapal.

Dari hasil survey diketahui, bahwa kapal KM ADRI XLIV menggunakan system konstruksi kerangka melintang.

\section{Konstruksi Geladak}

Geladak disamping berfungsi untuk kekedapan kapal, juga untuk melindungi barangbarang muatan dan ruang tempat tinggal ABK serta penumpang. Selanjutnya, geladak juga berfungsi menambah kekuatan memanjang kapal dan sebagian juga kekuatan melintang. Oleh sebab itu geladak harus betul-betul kedap air.

\section{Geladak Kekuatan}

Yang dimaksud geladak kekuatan menurut BKI adalah geladak menerus teratas yang merupakan bagian utama sebelah atas untuk kekuatan memanjang kapal.

Selain itu juga geladak bangunan atas yang termasuk bagian 0,4 L tengah kapal dan panjangnya melebihi 0,15 L. Jika panjang bangunan atas ini kurang dari 12 m, maka geladaknya tidak termasuk geladak kekuatan.

\section{Konstruksi Geladak pada system Konstruksi Kerangka Melintang}

Konstruksi geladak pada system ini terdiri dari balok-balok geladak yang dipasang melintang, dimana pada ujung-ujungnya ditumpu oleh gadinggading yang diikat dengan bracket. Pada bagian tengah, balok-balok geladak ditumpu oleh penumpu geladak tengah, dan diantara penumpu tengah dan ujung-ujung balok geladak sebelah kiri/kanan ditumpu oleh satu atau dua penumpu geladak samping, dimana jumlah penumpu samping geladak tergantung dari ukuran lebar kapal.

Jarak penumpu geladak tengah dengan penumpu geladak samping dan jarak sesama penumpu geladak samping diberlakukan sama dengan jarak penumpu pada konstruksi alas.

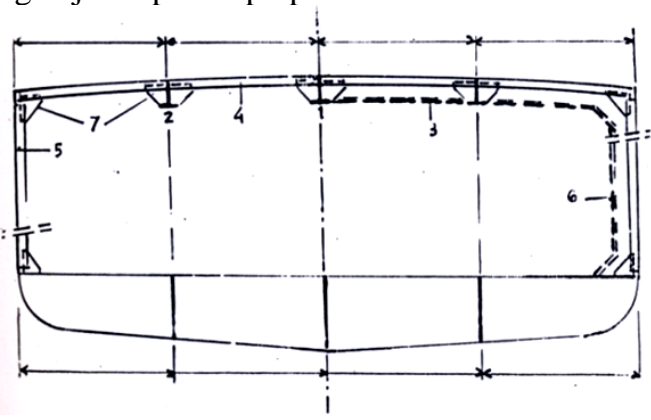

Gambar 3. Kontruksi Geladak 
Keterangan :

1. Penumpu Geladak Tengah

2. Penumpu Geladak Samping

3. Balok Geladak Kekuaan

4. Balok Geladak

5. Gading

6. Gading Besar

7. Bracket

Balok-balok geladak melintang dapat menggunakan profil siku (L) atau plat dengan bulb (I) dan dipasang pada tiap jarak gading, tetapi pada jarak tertentu dipasang balok geladak besar/balok geladak kekuatan.

Balok-balok geladak melintang dapat dipasang menerus/menembus penumpu geladak tengah maupun penumpu geladak samping, apabila ukuran tinggi plat tegaknya kurang dari setengah ukuran plat bilah penumpu geladak tengah maupun penumpu geladak samping dan diikat dengan bracket pada kedua sisinya.

Tetapi apabila melebihi ukuran tersebut, maka balok geladak harus terputus dan diikat juga dengan bracket.
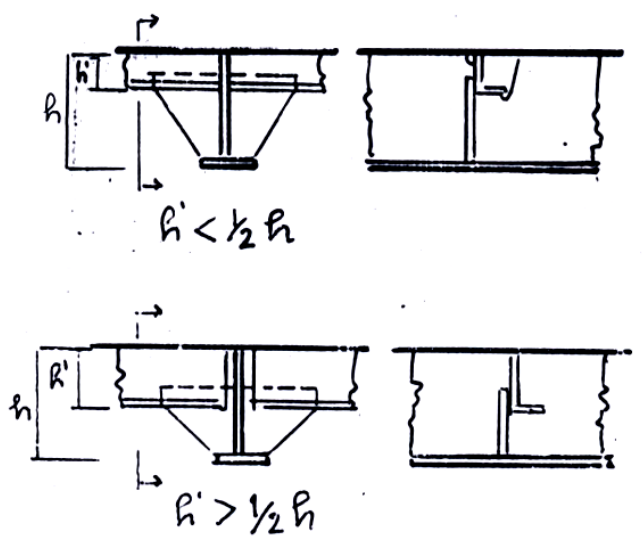

Gambar 4. Pemasangan balok pada geladak

Penumpu geladak tengah dan penumpu geladak samping merupakan tumpuan balok-balok geladak, oleh karena itu modulusnya besar dan biasanya profilnya berbentuk T. Begitu juga balok geladak besar/kekuatan yang dipasang antara $3 \mathrm{~s} / \mathrm{d} 5$ jarak gading, Bentuk profilnya adalah T.

\section{PEMBAHASAN}

Analisa konstruksi pada kapal dapat dilakukan dengan perhitungan, yang mana perhitungan-perhitungan dapat menggunakan beberapa rule yang ada, dalam hal ini perhitungan menggunakan rule dari Biro Klasifikasi Indonesia volume II (Rules for The Classification and Construction of Seagoing Steel Ships tahun 2006). Dan setelah diadakan survey dikapal, diketahui bahwa kapal KM ADRI XLIV menggunakan system konstruksi kerangka melintang, dimana pada tiaptiap gadingnya, baik gading-gading utama (Main Frame) maupun gading-gading besar (Web Frame) merupakan Ring Construction, sehingga beban yang ada pada geladak (deck) akan disalurkan ke lambung dan alas. Oleh karena itu perhitungan dilakukan pada tiga bagian konstruksi tersebut.

Data-data ukuran utama kapal (Principal Dimension)

$$
\begin{aligned}
& \text { Length Over All (LOA) } \quad=66,60 \mathrm{~m} \\
& \text { Length Water Line (LWL) } \quad=62,40 \mathrm{~m} \\
& \text { Length Between Perp. (LBP) }=60,60 \mathrm{~m} \\
& \text { Breadth }(B) \quad=13,50 \mathrm{~m} \\
& \text { Depth }(\mathrm{H}) \quad=5,00 \mathrm{~m} \\
& \text { Draught }(T) \quad=2,45 \mathrm{~m}
\end{aligned}
$$

Perhitungan Beban (design load) rule BKI section 4. Beban Alas Kapal (load on the ship's bottom)

$$
\begin{aligned}
& \mathrm{Pb}=10 \times \mathrm{T}+\mathrm{Po} \times \mathrm{Cf} \quad\left(\mathrm{KN} / \mathrm{m}^{2}\right) \\
& \text { dimana : } \\
& \mathrm{T} \quad=2,45 \mathrm{~m} \text { (sarat kapal) } \\
& \text { Po } \quad=2,1 \times(C b+0,7) \times \text { Co } \times C_{L} \times f \times C_{R W} \\
& \text { Co } \quad=\frac{L}{25}+4,1 \quad \text { for } \mathrm{L}<90 \mathrm{~m} \\
& =\frac{60,60}{25}+4,1 \\
& =6,524 \\
& \mathrm{C}_{\mathrm{L}}=\sqrt{\frac{L}{90}} \quad \text { for } \mathrm{L}<90 \mathrm{~m} \\
& =\sqrt{\frac{60,60}{90}} \\
& =0,82 \\
& \text { f } \quad=1 \\
& \mathrm{C}_{\mathrm{RW}}=1,0 \text {; for unlimited service range } \\
& \text { Po } \quad=2,1 \times(0,68+0,7) \times 6,524 \times 0,82 \times 1,0 \\
& =15,50\left(\mathrm{KN} / \mathrm{m}^{2}\right) \\
& \text { Cf } \quad=1,0 ; \text { distributor factor at midship } \\
& \mathrm{Pb} \quad=10 \times \mathrm{T}+\mathrm{Po} \times \mathrm{Cf} \quad\left(\mathrm{KN} / \mathrm{m}^{2}\right) \\
& =10 \times 2,45+15,50 \times 1,0 \\
& =40 \quad\left(\mathrm{KN} / \mathrm{m}^{2}\right)
\end{aligned}
$$

Beban Sisi Kapal (load on ships side)

$$
\text { Ps } \quad=10 \times(T-Z)+\text { Po } \times \text { Cf } \times\left(1+\frac{Z}{T}\right)
$$

$\left(\mathrm{KN} / \mathrm{m}^{2}\right)$, for below load waterline dimana :

$$
\begin{aligned}
& \mathrm{T}=2,45 \mathrm{~m} \\
& \mathrm{Z} \quad=1 / 3 \times \mathrm{T} \quad(\mathrm{m}) \text {; vertical } \\
& =1 / 3 \times 2,45 \quad \text { above baseline } \\
& =0,816 \mathrm{~m} \\
& \text { Po }=15,50\left(\mathrm{KN} / \mathrm{m}^{2}\right) \\
& \text { Cf } \quad=1,0
\end{aligned}
$$$$
\text { Ps } \quad=10 \times(\mathrm{T}-\mathrm{Z})+\text { Po } \mathrm{x} \text { Cf } \mathrm{x}\left(1+\frac{Z}{T}\right)
$$

$\left(\mathrm{KN} / \mathrm{m}^{2}\right)$

$$
\begin{aligned}
& =10 \times(2,45-0,816)+15,50 \times 1,0 \times \\
& \left(1+\frac{0,816}{2,45}\right) \\
& =37 \quad \mathrm{KN} / \mathrm{m}^{2}
\end{aligned}
$$


Beban pada Geladak Muatan (load on cargo deck)

PL = Pc X $(1+a v)$

$\left(\mathrm{KN} / \mathrm{m}^{2}\right)$

dimana :

$$
\begin{aligned}
& \text { Pc }=15 \quad \mathrm{KN} / \mathrm{m}^{2} \\
& \text { Av } \quad=\text { F x m } \\
& \text { F } \quad 0,11 \times \frac{v o}{\sqrt{L}} ; \\
& \quad \text { vo }=10,00 \text { knot (ship speed) } \\
& =0,11 \times \frac{10}{\sqrt{60,60}} \\
& =0,141 \quad=1,0 ; \text { for } 0,2 \leq \mathrm{X} / \mathrm{L} \leq 0,7 \\
& \text { m } \quad=0,141 \times 1,0 \\
& \text { Av } \quad=0,141 \\
& \text { PL }=15 \times(1+0,141) \\
& =17,12\left(\mathrm{KN} / \mathrm{m}^{2}\right)
\end{aligned}
$$

Perhitungan Tebal Plat

Tebal Plat Alas (bottom plating)

$$
\mathrm{t}_{\mathrm{B}} \quad=1,9 \times \mathrm{nf} \times \mathrm{ax} \sqrt{\mathrm{Pbxk}}+\mathrm{tk} \quad(\mathrm{mm})
$$

dimana :

$$
\begin{array}{ll}
\mathrm{nf} & =1,0 ; \text { for transverse frame } \\
\mathrm{a} & =0,6 \mathrm{~m} ; \text { frame spacing } \\
\mathrm{Pb} & =40 \quad \mathrm{KN} / \mathrm{m}^{2} ; \\
& \text { load on the ship's bottom } \\
\mathrm{k} & =1,0 ; \text { material factor } \\
\mathrm{tk} & =1,5 ; \text { corrosion factor }
\end{array}
$$

$t_{B}$

$$
\begin{aligned}
& =1,9 \times 1,0 \times 0,6 \times \sqrt{40 \times 1,0}+1,5 \\
& =8,71 \mathrm{~mm} ; \text { on ship }=10,00 \mathrm{~mm}
\end{aligned}
$$

Tebal Plat Sisi (side shell plating)

Rule BKI 2006 ; sec. 6 e.1.1 (for L < 90 m)

$$
\text { ts } \quad=1,9 \times \mathrm{nf} \times \mathrm{ax} \sqrt{P s \times k}+\mathrm{tk} \quad(\mathrm{mm})
$$
dimana :

$$
\begin{aligned}
& \text { nf } \quad=1,0 \\
& \mathrm{a}=0,6 \mathrm{~m} \\
& \text { Ps } \quad=37,00 \mathrm{KN} / \mathrm{m}^{2} \\
& \text { (load on the ship's side) } \\
& \mathrm{k}=1,0 \\
& \mathrm{tk}=1,5
\end{aligned}
$$

ts $\quad=1,9 \times 1,0 \times 0,6 \times \sqrt{37 \times 1,0}+1,5$

$=8,43 \mathrm{~mm}$; on ship $=10,00 \quad \mathrm{~mm}$

Tebal Plat Geladak (deck plating)

Rule BKI 2006 ; sec. 7 (for $\mathrm{L}<90 \mathrm{~m}$ )

$$
\mathrm{t}_{\mathrm{D}} \quad=1,9 \times \mathrm{nf} \times \mathrm{a} \times \sqrt{P_{D} x t}+\mathrm{tk}
$$

dimana :

$$
\begin{aligned}
& \text { nf } \quad=1,0 \\
& \text { a } \quad=0,6 \mathrm{~m} \\
& \mathrm{P}_{\mathrm{D}} \quad=17,12 \mathrm{KN} / \mathrm{m}^{2} \\
& \text { (load on cargo deck) } \\
& \mathrm{k}=1,0 \\
& \text { tk }=1,5
\end{aligned}
$$

$\mathrm{t}_{\mathrm{D}} \quad=1,9 \times 1,0 \times 0,6 \times \sqrt{17,12 \times 1,0}+1,5$

$=6,21 \mathrm{~mm}$

$$
\begin{aligned}
\mathrm{t}_{\mathrm{D} \text { min }} & =(4,5+0,05 \times \mathrm{L}) \sqrt{t} \\
& =(4,5+0,05 \times 60,60) \sqrt{1} \\
& =7,27 \quad \text { mm } ; \text { on ship }=10,00 \quad \mathrm{~mm}
\end{aligned}
$$

Perhitungan Balok Geladak (deck beam) dan penumpu balok geladak (centre deck girder).

Untuk menentukan ukuran material deck beam dan center/deck girder terlebih dahulu dihitung modulusnya.

Balok Geladak (deck beam)

Modulus penampang deck beam, rule BKI sec. 10.B.1

$$
\begin{array}{ll}
\mathrm{W} & =\mathrm{c} \times \mathrm{a} \times \mathrm{P}^{2} \mathrm{l}^{2} \mathrm{x} \mathrm{k} \quad\left(\mathrm{cm}^{3}\right) \\
\text { dimana : } & \\
\mathrm{c} & =0,75 \\
\mathrm{a} & =0,6 \mathrm{~m} ; \text { deck beam's space } \\
\mathrm{P} & =17,12 \mathrm{KN} / \mathrm{m}^{2} \\
\mathrm{l} & =2,25 \mathrm{~m} ; \text { deck girder space } \\
\mathrm{k} & =1 \\
\mathrm{~W} & =0,75 \times 0,6 \times 17,12 \times(2,25)^{2} \times 1 \\
& =39,00 \mathrm{~cm}^{3}
\end{array}
$$

Dari tabel profil didapat

$\mathrm{W} \quad=39,00 \mathrm{KN} / \mathrm{m}^{2}$; material L 80.65.6 ; on ship L 80.80 .8

Penumpu Balok Geladak (center, side deck girder)

Modulus penampang center, side deck girder

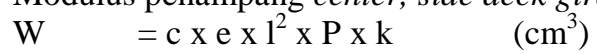

dimana :

$$
\begin{array}{ll} 
& \mathrm{e} \quad=2,25 \mathrm{~m} \text {; deck girder's space } \\
\mathrm{l} \quad=3,0 \mathrm{~m} \text {; web beam's space } \\
\mathrm{W} & =0,75 \times 2,25 \times(3,0)^{2} \times 17,12 \times 1 \\
= & 277,34 \mathrm{~cm}^{3}
\end{array}
$$

Dari modulus penampang $\mathrm{W}=277,34 \mathrm{~cm}^{3}$ didapat ukuran material T 225.8 FP 100.8

Koreksi modulus

$$
\begin{aligned}
\mathrm{F} & =50 \times 1 \\
\mathrm{fs} & =50 \quad \mathrm{~cm}^{2} \\
& =22,5 \times 0,8 \\
\mathrm{f} & =18 \quad \mathrm{~cm}^{2} \\
& =10 \times 0,8 \\
\mathrm{fs} / \mathrm{f} & =8 \quad \mathrm{~cm}^{2} \\
\mathrm{f} / \mathrm{F} & =0,36 \\
& =8 / 50 \\
& =0,16
\end{aligned}
$$

Dari diagram didapat $\mathrm{W}=0,25$

$$
\begin{aligned}
\mathrm{Wk} & =\mathrm{W} \times \mathrm{F} \times \mathrm{h} \\
& =0,25 \times 50 \times 22,5 \\
& =281,25 \mathrm{~cm}^{3}
\end{aligned}
$$

$\mathrm{Wk}>\mathrm{W}$ perhit

On ship T 350.8 FP 200.8 ; W $=850 \mathrm{~cm}^{3}$

$\mathrm{W}$ terpasang $>\mathrm{W}$ rule

\section{Side Deck Girder with Wheel House}

Modulus penampang penumpu samping pada sisi ambang palka

Rule BKI 2001. sec. 10.B.4.1

$\mathrm{W} \quad=\mathrm{cxexl}^{2} \times \mathrm{Pxk} \quad\left(\mathrm{cm}^{3}\right)$

dimana : 


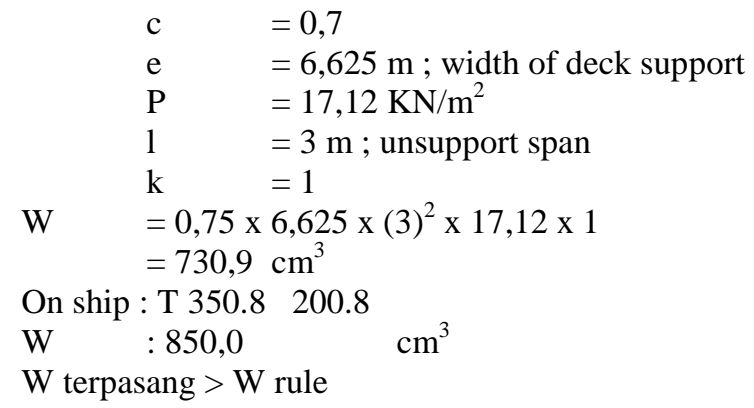

\section{Analisa Visual dari Hasil Survey}

Setiap konstruksi yang terpasang dikapal haruslah memenuhi standart mutu yang telah ditentukan oleh biro klasifikasi. Tidak dipenuhinya syarat yang ada akan secara langsung maupun dalam jangka tertentu terhadap kehandalan konstruksi dari badan kapal tersebut. Selain dari perhitungan, pemasangan material juga harus sesuai dengan rule yang ada, posisi pemasangan, bentuk dari potonganpotongan yang tepat sehingga distribusi tegangan dapat sesuai dengan hasil perencanaan.

Dari hasil survey dapat diketahui bahwa, menunjuk point 1 (kerusakan pada bagian belakang cargo hold)

Terjadinya kerusakan tersebut dimungkinkan oleh adanya missaligment antara stay bulwark dengan balok geladak pada bagian tersebut. Adanya beban tekuk antara side girder no. 4 dengan gading yang arahnya keatas yang menyebabkan retak arah vertikal pada siku balok geladak. Hal ini berhubungan dengan beban yang diijinkan untuk konstruksi tersebut.

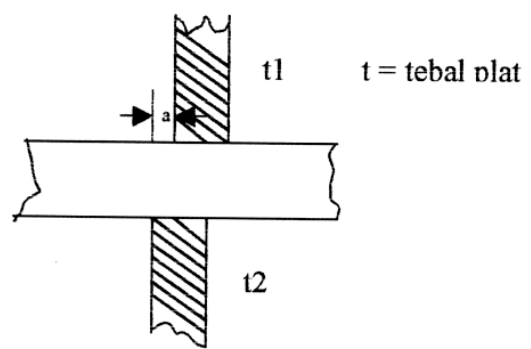

Gambar 5. Kerusakan akibat missaligment

Sarananya adalah pemasangan stay bulwark harus sesuai inline dengan balok geladak. Menurut standart mutu yang ada pemasangan stay bulwark harus inline jarak missaligment maksimal yang diijinkan sebesar a $<1 / 3$ 12. Kondisi dikapal menunjukkan jarak tersebut melebihi dari jarak yang telah ditentukan. Perlunya penambahan bracket antara side girder no. 5 dengan balok geladak pada frame 32 ; 33 ; 35 ukuran dan posisi sesuai gambar 6.
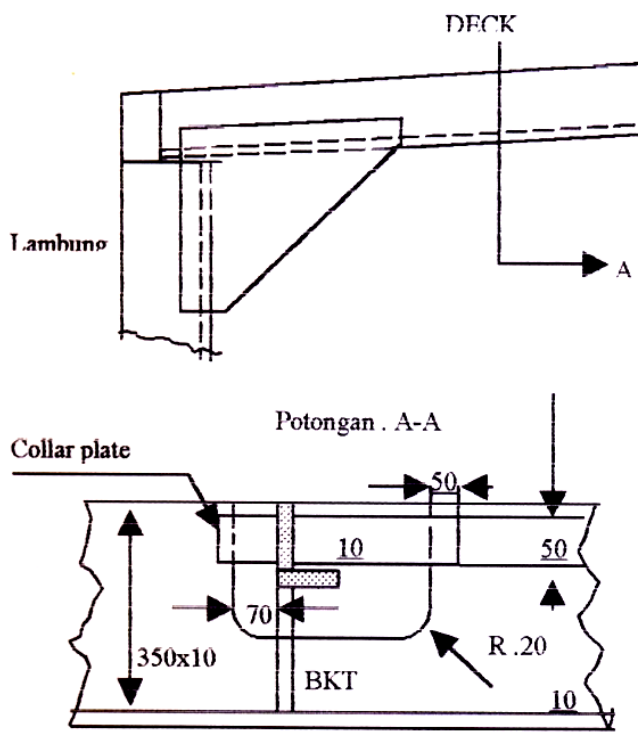

Gambar 6. Ukuran dan posisi balok

Kurang sempurnanya pengelasan disekitar bracket . sempurnanya pengelasan sangat mempengaruhi kekuatan konstruksi, karena pengelasan merupakan hal utama yang mengikat /menghubungkan tiap-tiap konstruksi hingga menjadi sebuah kapal.

Dari hasil pengamatan, kurangnya round weld serta posisi pengelasan haruslah sesuai rule yang telah ditentukan. Secara garis besar dapat dilihat seperti pada gambar 7 .

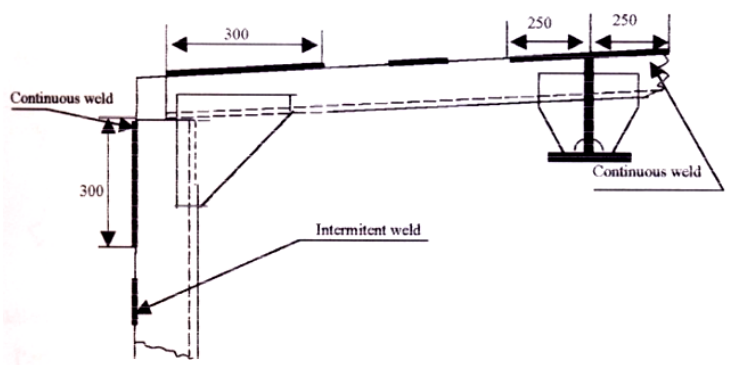

Gambar 7. Kontruksi pengelasan

Menunjuk poin 2 (kerusakan di cargo hold depan). Terjadinya keretakan pada side girder no. 5 pada frame 78 kanan dan kiri. Posisi keretakan terjadi pada daerah tekukan plat geladak dan bagian sudut lubang penembusan balok geladak. Timbulnya keretakan pada plat girder dimungkinkan adanya kesalahan pemotongan pada lubang collar seperti pada gambar 8 . 


\section{KONDISI DI LAPANGAN}

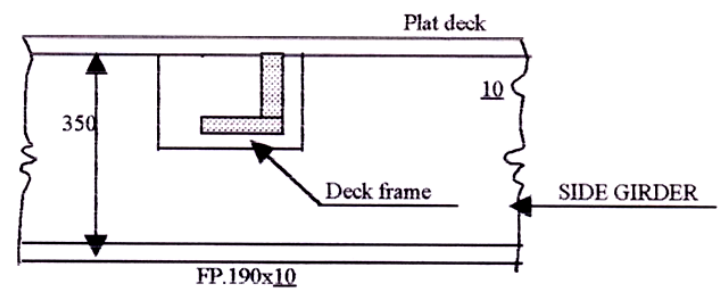

Gambar 8. Kesalahan lubang collar

Tidak adanya penerusan kekuatan dari side girder ke balok geladak. Tidak inlinenya antara stay bulwark dengan balok geladak juga dapat menimbulkan getaran didaerah tersebut.

Sesuai standart yang ada pemotongan lubang collar haruslah seperti pada Gambar 9.

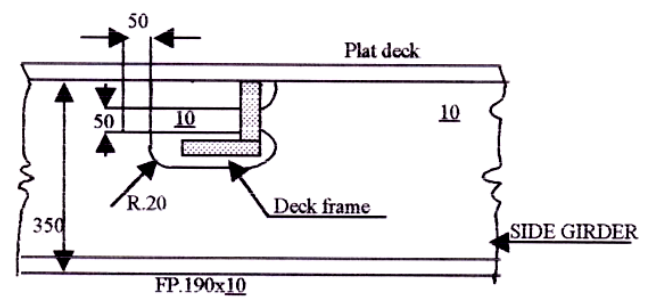

Gambar 9. Standar pemotongan lubang collar

Bagian yang retak supaya diganti minimal satu kali jarak gading.

Catatan : penambahan bracket dua sisi.

Perlu ditambahkan bracket dan collar plate pada frame 77 ; 78 dan 79

\section{KESIMPULAN DAN SARAN}

Dari hasil perhitungan dan survey yang telah dilakukan dapat diambil kesimpulan bahwa dari hasil perhitungan yang dalam hal ini menggunakan rule dari BKI volume II tahun 2006 diperoleh hasil sebagai berikut :

\begin{tabular}{|l|c|c|}
\hline & On ship & Perhitungan \\
\hline Bottom Plate Thickness & $10 \mathrm{~mm}$ & $8,71 \mathrm{~mm}$ \\
\hline Side Shell Plate Thickness & $10 \mathrm{~mm}$ & $8,43 \mathrm{~mm}$ \\
\hline Deck Plate Thickness & $10 \mathrm{~mm}$ & $7,27 \mathrm{~mm}$ \\
\hline $\begin{array}{l}\text { Modulus Penampang Main } \\
\text { Frame }\end{array}$ & $57 \mathrm{~cm}^{3}$ & $46,19 \mathrm{~cm}^{3}$ \\
\hline $\begin{array}{l}\text { Modulus Penampang } \\
\text { Web Frame }\end{array}$ & $570 \mathrm{~cm}^{3}$ & $217,4 \mathrm{~cm}^{3}$ \\
\hline $\begin{array}{l}\text { Modulus Penampang } \\
\text { Side Striner }\end{array}$ & $570 \mathrm{~cm}^{3}$ & $258,0 \mathrm{~cm}^{3}$ \\
\hline $\begin{array}{l}\text { Modulus Penampang } \\
\text { Deck Beam }\end{array}$ & $52 \mathrm{~cm}^{3}$ & $39,00 \mathrm{~cm}^{3}$ \\
\hline $\begin{array}{l}\text { Modulus Penampang Deck } \\
\text { Girder }\end{array}$ & $850 \mathrm{~cm}^{3}$ & $277,34 \mathrm{~cm}^{3}$ \\
\hline $\begin{array}{l}\text { Deck Girder with Wheel } \\
\text { Load }\end{array}$ & $850 \mathrm{~cm}^{3}$ & $730, \mathrm{~cm}^{3}$ \\
\hline
\end{tabular}

Tebal plat telah memenuhi syarat yang ditentukan sesuai rule dari BKI volume 2006.

Modulus penampang girder telah memenuhi syarat karena modulus yang terpasang lebih besar dari modulus hasil perhitungan.
Sesuai perhitungan dek sanggup menahan beban truk dan muatan seberat $10 \mathrm{ton} / \mathrm{m}^{2}$

Dari hasil survey yang telah dilkakukan didapat kesimpulan, keretakan yang terjadi karena konstruksi yang tidak sesuai dengan rule seperti :

- Missaligment

- Pengelasan yang tidak sempurna/tidak sesuai

- Pemotongan material yang tidak tepat.

- Beban geladak yang diijinkan menurut rule BKI dengan konstruksi yang ada hanya 10 ton $/ \mathrm{m}^{2}$. Pada prakteknya dibebani 15 s/d 30 ton $/ \mathrm{m}^{2}$.

Untuk mengatasi hal tersebut dapat dilakukan dengan :

- Konstruksi yang inline

- Pengelesan dan pemotongan material yang benar dan sempurna

- Penambahan beberapa konstruksi pada bagian main deck

- Perlu sosialisasi kepada crew kapal dengan beban berlebihan akan terjadi beberapa akibat antara lain : Konstruksi kapal bergetar pada semua konstruksi lambung baik mulai haluan kapal sampai kamar mesin. Akibat dari getarnya konstruksi banyak terjadi keretakan dimana-mana seperti penjelasan keretakan konstruksi didepan

\section{DAFTAR PUSTAKA}

1. Anonim,2001, Rules for the Classification and Construction of Seagoing Steel Ship. Biro Klasifikasi Indonesia, Jakarta.

2. Pussex, H J, 1975, Merchant Ship Construction, sixth Edition, Glasgow : Brown, Son and Ferguson, Ltd, Nautical Plubisher.

3. Taggart, Robert, 1980, Ship Design and Construction, The Society of Naval Architects and Marine Enginers.

4. Taylor, DA, 1985, Merchant Ship Construction, London, Boston Butterworths. 